\title{
Using Time Series of Satellite Images to Detect Vegetation Cover Change in Dhaka City
}

\author{
Sami Al Jaber, Amit Kumar Ghosh, Mallik Sezan Mahmud \\ Department of Geography and Environment, Faculty of Earth and Environmental Sciences, University of Dhaka, \\ Dhaka, Bangladesh \\ Email: riads45@yahoo.com
}

Received 24 September 2014; revised 24 October 2014; accepted 20 November 2014

Copyright (C) 2014 by authors and Scientific Research Publishing Inc.

This work is licensed under the Creative Commons Attribution International License (CC BY). http://creativecommons.org/licenses/by/4.0/

c) (i) Open Access

\begin{abstract}
The spatial land cover pattern of Dhaka city is restlessly altering as it has highest growing rates among megacities. Due to high urbanization rates, land use is changing from natural to man-made along with resource extractions that accelerate the land cover changes. This study has evidently given the glimpse of the raising concern by assessing the loss of vegetation coverage of Dhaka Metropolitan Area using multi-temporal Landsat imageries. 20 years satellite data have been used to detect the vegetation cover changes in Dhaka city with an interval of 10 years. Study reveals that 66.87 square kilometer vegetation coverage of Dhaka Metropolitan Area is lost during the whole time period. The rate of loss of vegetation coverage is very severe in Dhanmondi, Gulshan, Uttara, Demra, Mirpur, Sabujbagh, Ramna, Mohammadpur, Kafrul, Shyampur and so on. The overall precision of my Landsat-derived vegetation coverage maps is $\mathbf{9 2 . 5 \%}$.
\end{abstract}

\section{Keywords}

Dhaka Metropolitan Area, Vegetation Coverage, Landsat Imageries

\section{Introduction}

Vegetation is an important part of the global carbon cycle because trees and plants absorb carbon dioxide through photosynthesis [1]. By removing this greenhouse gas from the air, vegetation functions as terrestrial sinks meaning they store large amounts of carbon [2]. At any time, vegetation coverage accounts for as much as double the amount of carbon in the atmosphere [3]. Even as more anthropogenic carbon is produced, forests remove around three billion tons of anthropogenic carbon every year [4]. This amounts to about $30 \%$ of all carbon 
dioxide emissions from fossil fuels. Thus an increase in the overall forest cover around the world would tend to alleviate global warming. Therefore for the preservation of ecological balance in the urban environment, the spatial continuity of vegetation plays an imperative role [5].

\section{Study Area}

Dhaka Metropolitan Area (DMA) is the concerned area of this study and it is located between longitude $90^{\circ} 20^{\prime} \mathrm{E}$ \& $90^{\circ} 30^{\prime} \mathrm{E}$ and latitude $23^{\circ} 40^{\prime} \mathrm{N} \& 23^{\circ} 55^{\prime} \mathrm{N}$ (Figure 1). The total area of Dhaka Metropolitan Area (DMA) area is 306 sq. km [6]. Total population is about 9.3 million. In 1981 with ADB assistance an expatriate firm Shankland Cox Partnership and others undertook the project named Dhaka Metropolitan Area Integrated Urban Development Project. The master plan concept had by this time gone out of fashion and it was almost impossible to bring vast unplanned developments under any sort of rigid control. Nevertheless, many of the assumptions of the plan proved to be accurate and these later provided comprehensive basis for the future urban growth of Dhaka [7].

The vegetation coverage of Dhaka city has a great variety with indigenous and exotic species. According to an estimate of the Arboriculture Division of the Works Ministry, approximately $3.1 \mathrm{sq} . \mathrm{km}$ of total area of Dhaka city accommodate parks and gardens [8]. It is estimated that there are nearly 41 - 46 parks/gardens in Dhaka city of which Osmani Uddyan, Bahadur Shah Park, Botanical Garden, Zia Uddyan (Garden), Baldha Garden, Suhrawardi Uddyan, Ramna Park etc. are mentionable. The Botanical Garden, which is located at Mirpur in Dhaka city, covers around 0.84 sq. $\mathrm{km}$ of land with approximate 50,000 species of trees, herbs, and shrubs including large collection of aquatic plants, while Baldha garden with about 136 metres in length and 76 metres in width holds around 15,000 plants representing 672 species [9].

\section{Urban Area and Vegetation Definition}

There are many different definitions of urban areas, but typically they consist of densely settled territories with high population densities. The urban vegetation is the collection of woody and other vegetation that lies inside

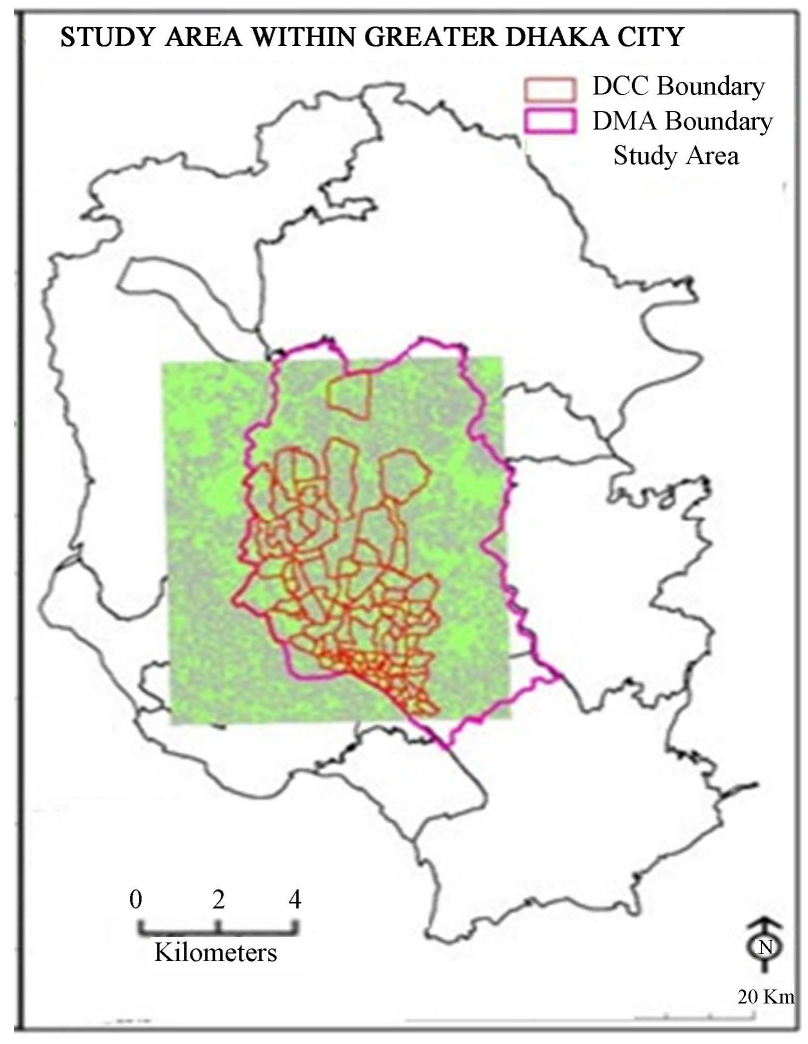

Figure 1. Study area. 
an urban area, or that forest structure which is frequently subjected to influences of an urban nature [10]. The urban forest includes trees along streets and other rights-of-way, trees in parks and residential yards, and in forested recreational areas near population centers. Other than trees, components of the urban forest system include other plants, animals, people and infrastructure. Natural processes within urban forests operate under an unusual suite of constraints because the areas are relatively small and isolated, are subject to frequent disturbance, and are impacted by polluted air and waste [10]. Trees are typically under greater stress in urban than in rural or undeveloped areas because of greater urban temperatures, soil compaction, restricted root zones, and variation in the intensity of light and wind caused by buildings and pavement [11]. Urban/periurban vegetation is also susceptible to pests and diseases, climate change and extremes, acid rain, and air pollution Because urban land-use patterns change rapidly in response to economic, social and environmental forces, urban forest planning and management require rapid, accurate, and systematic methods for acquiring information.

\section{Data and Method}

Remote sensing is a key application in global-change science for urban environment and land use/cover dynamics analysis. Quantitative remote sensing involves the prediction of in situ quantities based on remote measurements of radiation. This prediction problem relies on statistical or physically based models relating remote and in situ measurements [12].

In this research to scrutinize the loss of vegetation coverage for the Dhaka Metropolitan Area multi-temporal landsat Imageries are used (Table 1). For the sake of distinguishing the vegetation coverage of (DMA) Dhaka metropolitan area, Landsat5 TM image of 1989 and Landsat7 ETM+ image of 1999, 2009 were used. Spatial resolution of all these images was $30 \mathrm{~m}$. Band 4, 3, 2 was used for image classification.

\section{Calculation of NDVI = (NIR - RED $) /($ NIR + RED $)$}

The image datasets were preprocessed amid the maximum value composite (MVC) and cloud removed. For sub siding the image noises from the atmospheric clouds, particles, shadows, etc., we synthesized two 16-day composite NDVI images to one 32-day composite NDVI image in succession by using the MVC technique [13]. Even though the MVC technique diminishes the after-effects from the atmospheric clouds, particles, etc., there is still clouds pollution. For that reason, to resolve the dilemma, the composite images are processed using the best index slope extraction (BISE) methods [10]. where NDVIt -1 and NDVIt +1 indicate the NDVI values of time $\mathrm{t}-1$ and $\mathrm{t}$ correspondingly; dNDVIt $-1, \mathrm{t}$ and dNDVIt, $\mathrm{t}+1$ show the variation rate from $\mathrm{t}-1$ to $\mathrm{t}$ and from $t+1$ to $t$ correspondingly. Here, It is presumed that the pixel at time $t$ is affected by clouds if dNDVIt $-1, t$ and dNDVIt, $t+1$ are both exceed $20 \%$, then the $t$ time pixel value is corrected by the average of time $t-1$ and time $t+1$. We implemented the algorithm to identify the impure position point and smooth the NDVI time series data for all the pixels in our study periods not including the starting and ending points. For both the foremost and end pixels, the improved BISE technique is adopted: if dNDVI1, 2 is more than $20 \%$, the first pixel is substituted by the average of time 1 and time 2 . And in the end the last pixel value is prepared in the similar method.

\section{Data Processing Analysis}

For analyzing, processing and assimilating of spatial data to reach the objectives of the study digital imageprocessing software ENVI (v. 4.7) and vector data manipulation software ArcGIS (v. 9.3.1) were used. The images were "geo referenced" mosaicked and subset using a geo referenced shape files of Dhaka city (Figure 2).

Table 1. Data characteristics.

\begin{tabular}{|c|c|c|c|c|}
\hline \multirow{2}{*}{ Satellite Names } & \multicolumn{4}{|c|}{ Metadata } \\
\hline & Sensor & Bands & Date of Acquisition & Spatial Resolution \\
\hline Landsat 5 & $\mathrm{TM}$ & 4, 3, 2 (NIR, R, G) & 1989-06-04 & $30 \mathrm{~m}$ \\
\hline Landsat 7 & ETM+ & 4, 3, 2 (NIR, R, G) & 1999-10-19 & $30 \mathrm{~m}$ \\
\hline Landsat 7 & ETM+ & 4, 3, 2 (NIR, R, G) & 2009-09-30 & $30 \mathrm{~m}$ \\
\hline
\end{tabular}




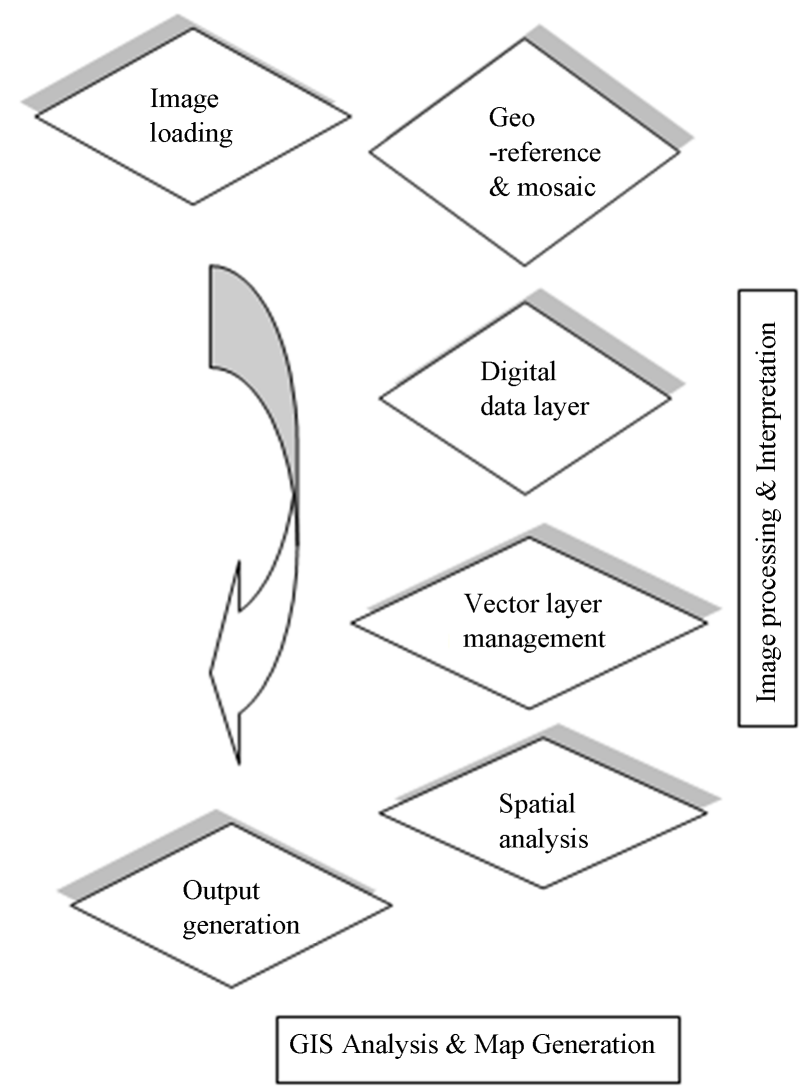

Figure 2. Conceptual framework.

After that the real vegetation cover is identified using the "vegetation demarcation tool of ENVI" [14]. For additional study through ArcGIS, resultant vegetation coverage of (DMA) is exported to shape files. The complete workflow can be illustrated as below (Figure 3). Vegetation demarcation works rapidly in ENVI to locate the existence of vegetation and to visualize its stage of dynamism. At some stage in the study the Landsat imageries are transformed to an NDVI output. In accordance with the brightness values density slicing of the images was done. Atmospheric rectification was avoided during doing the process. The density slicing really helps us to properly locate and visualize the existence of specific features and in my study the aim was to find a particular feature that is vegetation coverage.

The intensity that is used to categorize the vegetation cover can be displayed as below (Table 2). Only two noticeably recognized classes, the dense and the sparse were chosen to export as shape file (.shp) to analyze in the next phase. In the last stage of it, the vegetation cover analysis has been performed within ArcGIS desktop (9.3.1) by re-projecting, overlaying and computing the spatial distribution of the vegetation and its varying prototype in three different time period (Figures 4-6).

Change detection technique using land use and land cover maps is the basis of much land cover dynamics research. Specifically, a wide variety of remote sensing methods have been for detecting landuse and land cover change in bi-temporal categorical and multi-spectral imagery depending on the given spatial, spectral and temporal resolution of the available imagery and the computer capacities in regard to digital image processing [8]. The available imagery and the computer capacities in regard to digital image processing. Change detection procedures intend to find and, where appropriate, to interpret the alterations of objects or phenomenon between the different acquiring times $\mathrm{t} 1, \mathrm{t} 2 \ldots \mathrm{tn}$. When using multi-temporal remote sensing image data, the value of an image pixel or object at time $t 1$ can be compared with the value of the corresponding image pixel or object at time t2 in order to determine the degree of change [15]. The simplest method of change detection is to sum the differences between the spectral values of every band of the bi-temporal Landsat TM and ETM+ images. This method is available in almost all remote sensing processing software. The calculation result can precisely reflect the spectral change degree that is implicitly caused by the spatial object changes. However, because of the complexity 


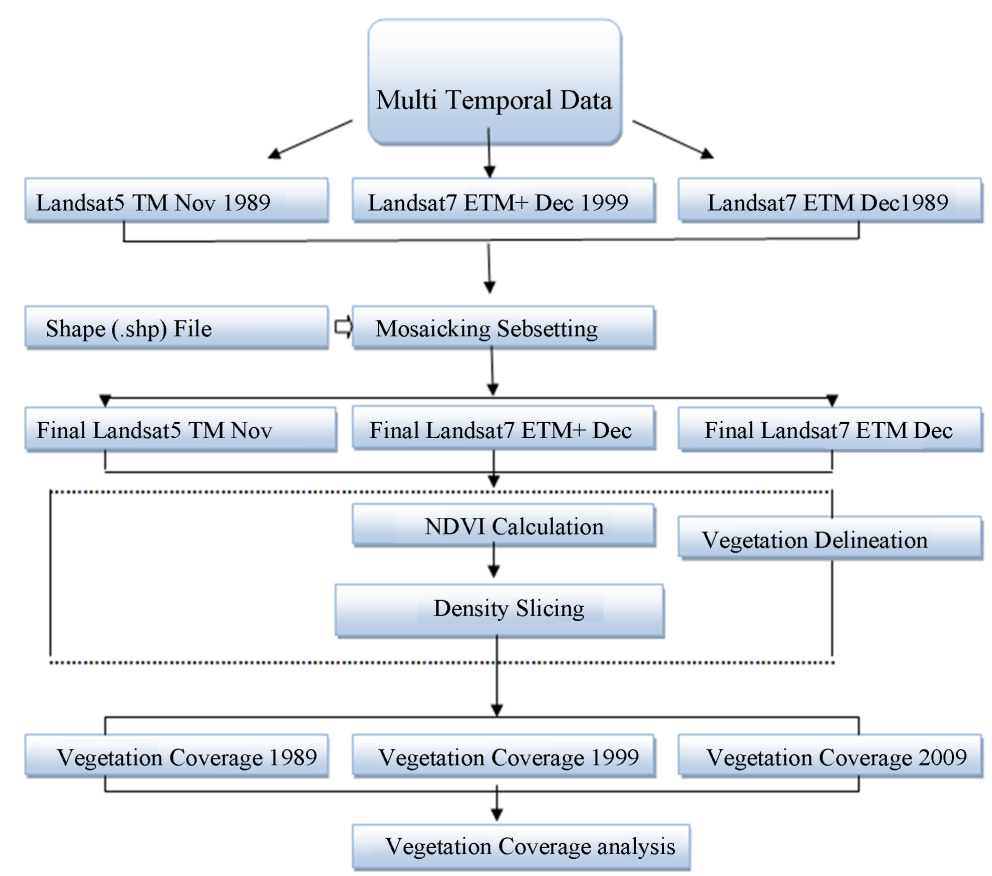

Figure 3. Flowchart of the NDVI analysis.

Table 2. Area of vegetation coverage of Dhaka Metropolitan Area (DMA) in square kilometers.

\begin{tabular}{|c|c|c|c|c|c|c|}
\hline \multirow{2}{*}{ Thana Names } & \multicolumn{2}{|c|}{1989} & \multicolumn{2}{|c|}{1999} & \multicolumn{2}{|c|}{2009} \\
\hline & Dense & Sparse & Dense & Sparse & Dense & Sparse \\
\hline Uttara & 2.40 & 4.50 & 1.24 & 2.90 & 0.96 & 1.16 \\
\hline Pallabi & 2.10 & 3.65 & 0.40 & 0.59 & 0.20 & 0.60 \\
\hline Cantonment & 5.26 & 4.70 & 3.01 & 4.45 & 1.00 & 1.82 \\
\hline Mirpur & 2.16 & 2.86 & 0.64 & 0.93 & 0.35 & 0.51 \\
\hline Kafrul & 3.30 & 4.32 & 1.10 & 1.30 & 0.78 & 0.82 \\
\hline Gulshan & 1.90 & 2.42 & 0.20 & 0.49 & 0.004 & 0.03 \\
\hline Badda & 1.06 & 2.6 & 0.98 & 1.57 & 0.6 & 1.03 \\
\hline Mohammadpur & 1.00 & 0.84 & 0.02 & 0.05 & 0.001 & 0.004 \\
\hline Tejgaon & 1.66 & 2.10 & 0.30 & 0.66 & 0.23 & 0.45 \\
\hline Khilgaon & 0.60 & 0.90 & 0.40 & 0.80 & 0.31 & 0.69 \\
\hline Dhanmondi & 0.78 & 1.13 & 0.12 & 0.37 & 0.09 & 0.15 \\
\hline Hazaribug & 0.20 & 0.61 & 0.02 & 0.06 & 0.0012 & 0.0028 \\
\hline Ramna & 2.15 & 0.90 & 1.10 & 0.46 & 0.84 & 0.18 \\
\hline Motijheel & 0.80 & 0.78 & 0.08 & 0.09 & 0.02 & 0.03 \\
\hline Sabujbug & 1.20 & 1.73 & 0.40 & 0.60 & 0.25 & 0.36 \\
\hline Lalbug & 0.93 & 1.10 & 0.65 & 0.98 & 0.24 & 0.45 \\
\hline Kotwali & 0.002 & 0.038 & 0.004 & 0.004 & 0.00001 & 0.0002 \\
\hline Sutrapur & 0.3 & 0.56 & 0.002 & 0.001 & 0.0012 & 0.0008 \\
\hline Demra & 3.60 & 7.34 & 2.40 & 3.50 & 1.00 & 1.03 \\
\hline Shyampur & 3.40 & 2.28 & 1.10 & 0.72 & 0.67 & 0.33 \\
\hline Kamrangichar & 0.67 & 1.41 & 0.0021 & 0.0279 & 0.00003 & 0.00007 \\
\hline Total & \multicolumn{2}{|c|}{84.07} & \multicolumn{2}{|c|}{35.952} & \multicolumn{2}{|c|}{17.1894} \\
\hline
\end{tabular}




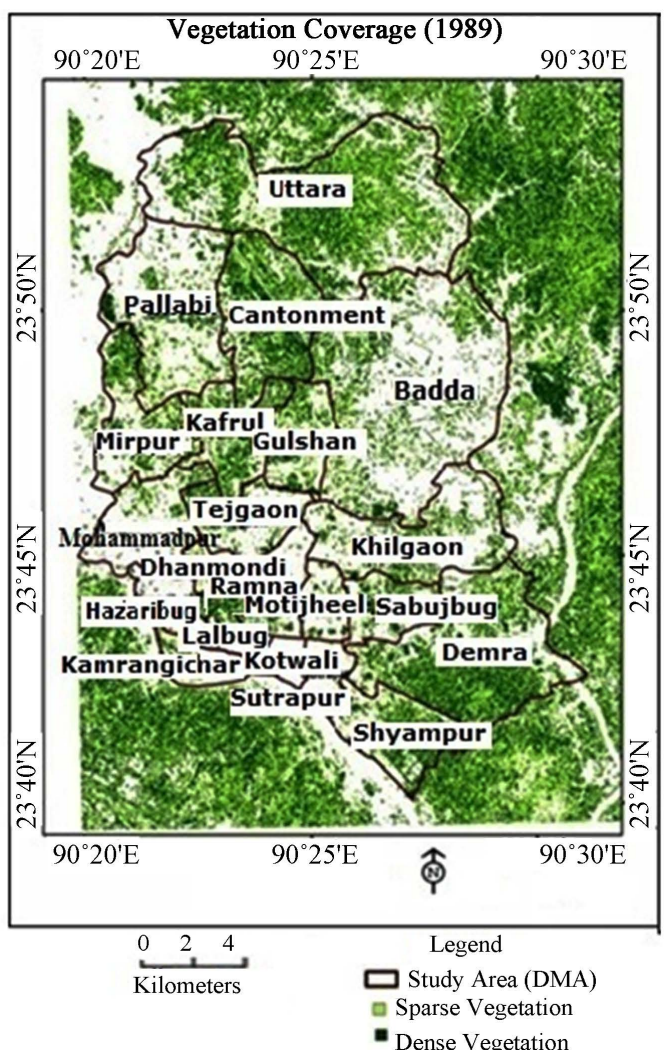

Figure 4. Vegetation coverage in 1989 in Dhaka Metropolitan area.

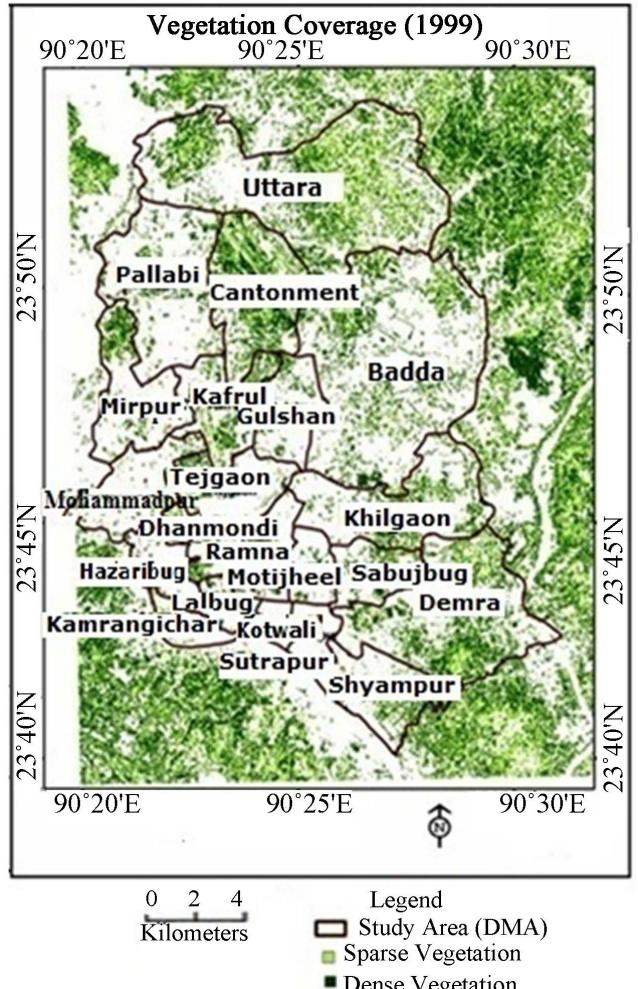

Figure 5. Vegetation coverage in 1999 in Dhaka Metropolitan area. 


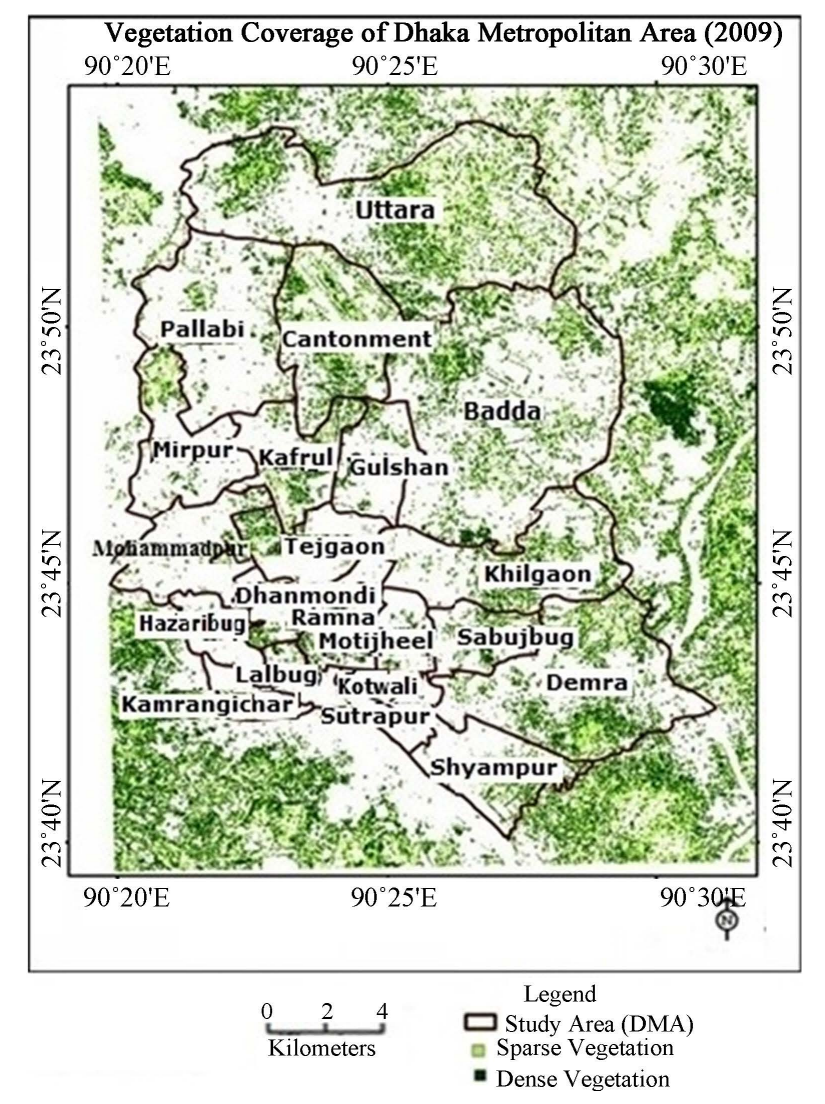

Figure 6. Vegetation coverage in 2009 in Dhaka Metropolitan area.

of object reflection, the same object may reflect a different spectrum at different times, or different objects may reflect the same spectrum at different times. Therefore, in practice spectral difference is always taken to be a reference. A more conventional method of change detection is to compare the differences based on the classified images; this is called post-classification comparison. It performs a pixel-by-pixel overlay of two thematic maps to generate a similarity map and associated statistics that indicate regions of disagreement of spatial objects. However, there are numerous examples in the literature of concerns about the limitations of the traditional methods. Fuzzy sets methods avoid the above limitations [10]. Fuzzy set theory and fuzzy topology are the ideal tools for defining fuzzy spatial objects theoretically, since fuzzy set theory is a natural extension of classical set theory and fuzzy topology is built based on fuzzy sets. The key issue of a fuzzy spatial object is its boundary. Besides the fuzzy boundary, several notions such as the core, the internal, the fringe, the frontier, the internal fringe and the outer of a fuzzy set are defined in fuzzy topological space. In general, the core is the crisp subset of the interior, and the fringe is a kind of boundary but shows a finer structure than the boundary of a fuzzy set in fuzzy topological space. A fuzzy map is more appropriate for representing a complex land use type, such as vegetation coverage, because it enables the pixels or polygons to have multiple memberships in the land use classes. So it is better to represent land cover objects directly in fuzzy representation. A methodology for change detection based on fuzzy reasoning consists of the following steps: generation of fuzzy land cover objects and derivation of differences of membership values; reasoning about changes of categorical fuzzy land covers, based on fuzzy polygons (fuzzy regions); reasoning about changes of land cover objects. The standard Change Vector Analysis (CVA) is a change detection tool that characterizes movement in spectral space over time in terms of magnitude and direction. The CVA approach defines a change vector as the difference vector between two vectors in an $\mathrm{n}$-dimensional ( $\mathrm{n}=$ number of change indicators) feature space, whereby these two vectors correspond to two observations of the same pixel at two different moments in time [16]. The change vector's length represents the magnitude of the change event in the spectral feature space, while its direction corresponds to the type of change. While vector length is a continuous variable, vector direction has an angular nature requiring some special handling. The other change detection techniques applied for forest ecosystem monitoring are Multi- 
temporal Spectral Mixture Analysis (MSMA), and maximum likelihood (ML) classification, Principal Components Analysis (PCA) techniques. The NDVI is expressed on a scale from +1 to -1 . For green vegetated surfaces in urban areas, near-infrared reflectance is always greater than red reflectance and therefore NDVI $>0$.

\section{Vegetation Scenario in DMA form 1989 to 2009}

The study has exposed the pattern and character of the interrelationship between urban sprawl and urban vegetation loss. The result of this study clearly shows that the vegetation coverage in Dhaka decreases significantly after 1989 (Table 2). Among 21 thanas the vegetation loss is most shocking in Uttara, Pallabi, Cantonment, Kafrul, Mirpur, Gulshan, Mohammadpur, Tejgaon, Khilgaon, Hazaribug, Dhanmondi, Ramna, Motijheel, Demra and in Badda. The outcome of the computation can be tabulated as follows (Table 3).

\section{Comparative Analyses of Vegetation Coverage}

The analysis in (Figure 6) indicates that the total vegetation coverage followed low reduction rate in Khilgaon, Hazaribug, Ramna, Sutrapur, Lalbug and in Kotwali thana. This change has very small impact of the total vegetation change scenario of this area. The study indicates that Badda lost 2 square kilometer of green cover during 1989-1999 period and in 1999-2009 she lost 2.05 square kilometer of green cover. The study clearly indicates the alarming reduction of vegetation coverage in Dhaka Metropolitan areas we can see the high rate of changing

Table 3. Loss of vegetation coverage in DMA from 1989 to 2009 in 10 years interval (Area in square kilometers).

\begin{tabular}{|c|c|c|c|}
\hline \multirow{2}{*}{ Thana Names } & \multicolumn{2}{|c|}{ Vegetation Lost } & \multirow{2}{*}{ Total Loss during 1989-2009 } \\
\hline & 1989-1999 & 1999-2009 & \\
\hline Uttara & 2.67 & 2.11 & 4.78 \\
\hline Pallabi & 4.76 & 0.19 & 4.95 \\
\hline Cantonment & 2.50 & 4.64 & 7.16 \\
\hline Mirpur & 3.45 & 0.71 & 4.16 \\
\hline Kafrul & 5.22 & 0.80 & 6.02 \\
\hline Gulshan & 3.44 & 0.66 & 4.10 \\
\hline Badda & 2.00 & 2.05 & 4.05 \\
\hline Mohammadpur & 1.77 & 0.07 & 1.835 \\
\hline Tejgaon & 2.79 & 0.29 & 3.08 \\
\hline Khilgaon & 0.30 & 0.20 & 0.50 \\
\hline Dhanmondi & 1.42 & 0.25 & 1.67 \\
\hline Hazaribug & 0.73 & 0.08 & 0.806 \\
\hline Ramna & 1.49 & 0.54 & 2.022 \\
\hline Motijheel & 1.40 & 0.13 & 1.53 \\
\hline Sabujbug & 1.93 & 0.39 & 2.32 \\
\hline Lalbug & 0.40 & 0.94 & 1.34 \\
\hline Kotwali & 0.04 & 0.0039 & 0.0399 \\
\hline Sutrapur & 0.85 & 0.0028 & 0.85 \\
\hline Shyampur & 5.04 & 3.87 & 8.91 \\
\hline Demra & 3.86 & 0.82 & 4.68 \\
\hline Kamrangichar & 2.05 & 0.0299 & 2.07 \\
\hline Total & 48.119 & 18.76 & 66.87 \\
\hline
\end{tabular}


vegetation coverage has prevailed in Dhanmondi, Gulshan, Cantonment, Pallabi, Mirpur, Mohmmadpur, Demra, Motijheel, Shyampur, Sabujbug, Kafrul, Uttara, Tejgaon and in Kamrangichar thana. So, rapid urbanization is heavily responsible for reducing green spaces in these areas.

\section{Trend of Loss and Projection}

Trend of vegetation loss in (Figure 7) is drawn in Microsoft Excel and it indicates that if the current trend of vegetation loss for last 20 years continues, there will be insignificant amount of vegetation in Dhaka Metropolitan Area (DMA). In 2029, insignificant amount of vegetation will be remained in DMA. In this case, $\mathrm{R}^{2}$ is 0.994 which is also highly significant.

\section{Accuracy Assessment}

Confusion Matrix or Contingency Matrix is one of the most means of expressing classification accuracy is the preparation of an "Error Matrix" [17]. It compares a group basis, the correlation between known reference data (Ground Truth) and the corresponding outcome of an automated classification. Such matrix is square, with the number of rows and column equal to the number of the categories whose classification is being assessed.

For accuracy assessment various points on the ground of Dhaka Metropolitan Area were selected where vegetation coverage and non vegetation coverage area were cross referenced with the satellite image of 2009 (Table 4). The locations for ground truthing were selected randomly all over the Dhaka Metropolitan Area.

\subsection{Producer's Accuracy}

Results from dividing the number of correctly classified points for each class (on the major diagonal) by the number of reference points "known" to be of that category (the column total). This value represents how well reference points of the ground cover type are classified [18].

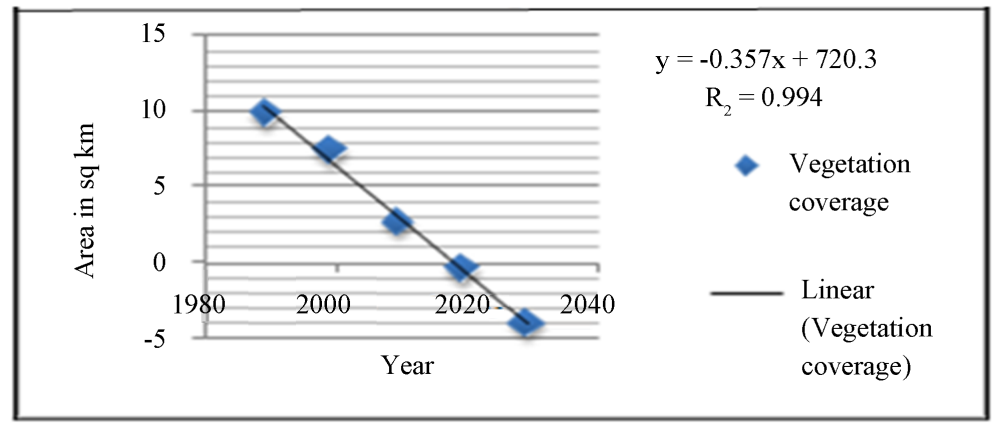

Figure 7. Trend of loss of vegetation coverage of dhaka metropolitan area.

Table 4. Accuracy assessment.

\begin{tabular}{|c|c|c|c|}
\hline \multirow{2}{*}{ Classification } & \multicolumn{3}{|c|}{ Referenced Data } \\
\hline & Vegetation & Non-Vegetation & Row Total \\
\hline Vegetation & 53 & 4 & 57 \\
\hline Non-Vegetation & 2 & 21 & 23 \\
\hline Column Total & 55 & 25 & 80 \\
\hline \multicolumn{2}{|c|}{ Producer's Accuracy } & \multicolumn{2}{|c|}{ User's Accuracy } \\
\hline \multicolumn{2}{|c|}{ Vegetation $=53 / 55=96.36 \%$} & \multicolumn{2}{|c|}{ Vegetation $=53 / 57=92.38 \%$} \\
\hline \multicolumn{2}{|c|}{ Non-vegetation $=21 / 25=84 \%$} & \multicolumn{2}{|c|}{ Non-vegetation $=21 / 23=91.30 \%$} \\
\hline \multicolumn{4}{|c|}{ Overall Accuracy: $(53+21) /(55+25)=74 / 80=92.5 \%$} \\
\hline
\end{tabular}




\subsection{User's Accuracy}

Computed by dividing the number of correctly classified points in each class by the total number of points that were classified in that class (the row total) represent the probability that a point classified into a given class actually represents that class on the ground [18].

\subsection{Overall Accuracy}

Computed by dividing the total number of correctly Classified points (i.e., the sum of the elements along the major diagonal) by the total number of reference points [18].

\section{Conclusion}

Green coverage is one of the most significant factors for supporting life and the living environment for any speedily growing cities (Department of Environment, BCAS and UNEP 2005), like Dhaka; not only for preserving sustainable human habitat but also for safeguarding from the negative effects of urban pollution and Urban Heat Island (UHI). Our study of temporal mapping of Dhaka Metropolitan Area (DMA) successfully demonstrates the shocking changes of decreasing urban forestry and vegetation coverage. Its area over the course of time; about $48.119 \mathrm{sq} \mathrm{km}$ area has been lost during 1989 to 1999 that stands overall $66.87 \mathrm{sq} \mathrm{km}$ of vegetation lost. It is an awful condition due to the high disintegration of the increasing pace of human activity in this region. The action not only is causing the demolition of landscape ecological processes and services, but also is degrading the biodiversity in urban areas. Furthermore, consistent landscape disintegration can also result in a pitiable quality of life in the urban environment. For that reason, an extensive green space management policy should be implemented for Dhaka Metropolitan Area that could support proper functioning of the ecosystem. This temporal urban map and database can help the planner and practitioners to build a model to monitor and predict the patterns and future trends of urbanization.

\section{Acknowledgements}

This research would have been impossible without some people so we would like to thank Dr. Rejuan Hossain Bhuiyan, Professor of Dhaka University, Dr. Touhida Rashid, Associate Professor of Dhaka University and a special thanks to Shafayet Uddin who is a Field Research Assistant at ICDDR, B.

\section{References}

[1] Bashar, M.A. (2007) Urban Forestry: Imperative for Life in City. The Daily Star, Dhaka.

[2] Landsat Project Science Office (2000) Landsat 7 Scince Data Users Handbook. Goddard Space Flight Center. http://landsathandbook.gsfc.nasa.gov/pdfs/Landsat7_Handbook.pdf

[3] Alam, M. and Rabbani, M.G. (2007) Vulnerabilities and Responses to Climate Change for Dhaka. Environment and Urbanization, 19, 81-97. http://dx.doi.org/10.1177/0956247807076911

[4] Levien, L.M., Roffers, P., Maurizi, B., Suero, J., Fischer, C. and Huang, X. (1999) A Machine-Learning Approach to Change Detection Using Multi-Scale Imagery. American Society of Photogrammetry and Remote Sensing, Portland.

[5] Rahman, S., Hasan, S.M., Islam, M.A. and Maitra, M.K. (2011) Temporal Change Detection of Vegetation Coverage of Dhaka Using Remote Sensing. International Journal of Geomatics and Geosciences, 2, 481-490.

[6] Goward S.N., Xue, Y. and Czajkowski, K.P. (2000) Bibliography Evaluating Land Surface Moisture Conditions from the Remotely Sensed Temperature/Vegetation Index Measurements. An Exploration with the Simplified Simple Biosphere Model. Remote Sensing of Environment, 79, 225-242. http://dx.doi.org/10.1016/s0034-4257(01)00275-9

[7] Hossain, S. (2008) Rapid Urban Growth and Poverty in Dhaka City. Bangladesh e-Journal of Sociology, 5, 1-24.

[8] Kabir, A. and Parolin, B. (2012) Planning and Development of Dhaka-A Story of 400 Years. 15th International Planning History Society Conference, Cities, Nations and Regions in Planning History, Sao Paulo, 1-20.

[9] Shahabi, H., Ahmad, B.B., Mokhtari, M.H. and Zadeh, M.A. (2012) Detection of Urban Irregular Development and Green Space Destruction Using Normalized Difference Vegetation Index (NDVI), Principal Component Analysis (PCA) and Post Classification Methods: A Case Study of Saqqez City. International Journal of Physical Sciences, 7, 2587-2595. http://dx.doi.org/10.5897/IJPS12.009

[10] Wang, Q., Adiku, S., Tenhunen, J. and Granier, A. (2005) On the Relationship of NDVI with Leaf Area Index in a Deciduous Forest Site. Remote Sensing of Environment, 94, 244-255. http://dx.doi.org/10.1016/j.rse.2004.10.006 
[11] Dewan, A.M. and Yamaguchi, Y. (2009) Land Use and Land Cover Change in Greater Dhaka, Bangladesh: Using Remote Sensing to Promote Sustainable Urbanization. Nagoya. http://dx.doi.org/10.1016/j.apgeog.2008.12.005

[12] Zipperer, W.C., Sisinni, S.M. and Pouyat, R.V. (1997) Urban Tree Cover: An Ecological Perspective. Urban Ecosystems, 1, 229-246. http://dx.doi.org/10.1023/A:1018587830636

[13] Alam, M. and Rahman, A.A. (2003) Dhaka City State of Environment. United Nations Environment Programme, Dhaka.

[14] Mahmud, M.S., Masrur, A., Ishtiaque, A., Haider, F. and Habiba, U. (2011) Remote Sensing \& GIS Based SpatioTemporal Change Analysis of Wetland in Dhaka City, Bangladesh. Journal of Water Resource and Protection, 3, 781-787. http://dx.doi.org/10.4236/jwarp.2011.311088

[15] Forman, R.T.T. (1995) Some General Principles of Landscape and Regional Ecology. Landscape Ecology, 10, $133-142$. http://dx.doi.org/10.1007/BF00133027

[16] Islam, S. (2003) National Encyclopedia of Bangladesh. Banglapedia Trust, Asiatic Society of Bangladesh, Dhaka.

[17] Leitmann, J., Bartone, C. and Bernstein, J. (1992) Environmental Management and Urban Development Issues and Options for Third World Cities. Environment and Urbanization, 4, 131-140. http://dx.doi.org/10.1177/095624789200400213

[18] Map Accuracy Assessment. (n.d).

http://www.nateko.lu.se/Courses/NGEA05/Kurshemsida/F\%F6rel\%E4sningar/Assessment\%20of\%20Classification\%2 $\underline{\text { 0Accuracy.pdf }}$ 
Scientific Research Publishing (SCIRP) is one of the largest Open Access journal publishers. It is currently publishing more than 200 open access, online, peer-reviewed journals covering a wide range of academic disciplines. SCIRP serves the worldwide academic communities and contributes to the progress and application of science with its publication.

Other selected journals from SCIRP are listed as below. Submit your manuscript to us via either submit@scirp.org or Online Submission Portal.
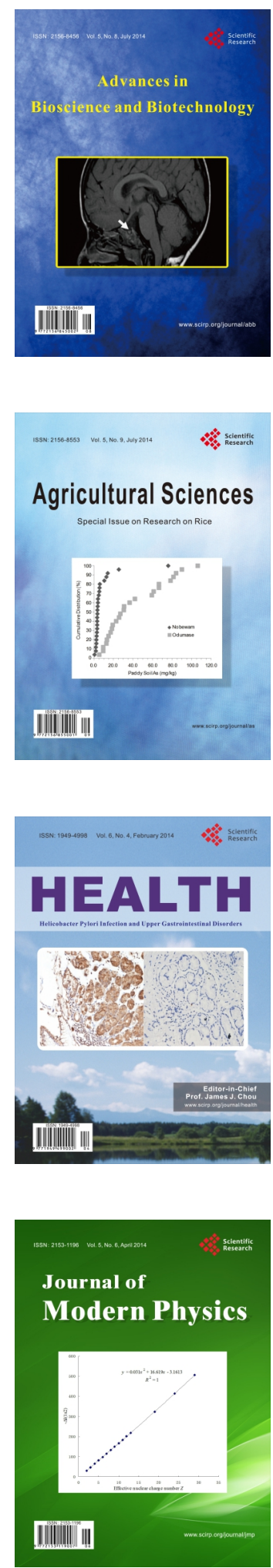
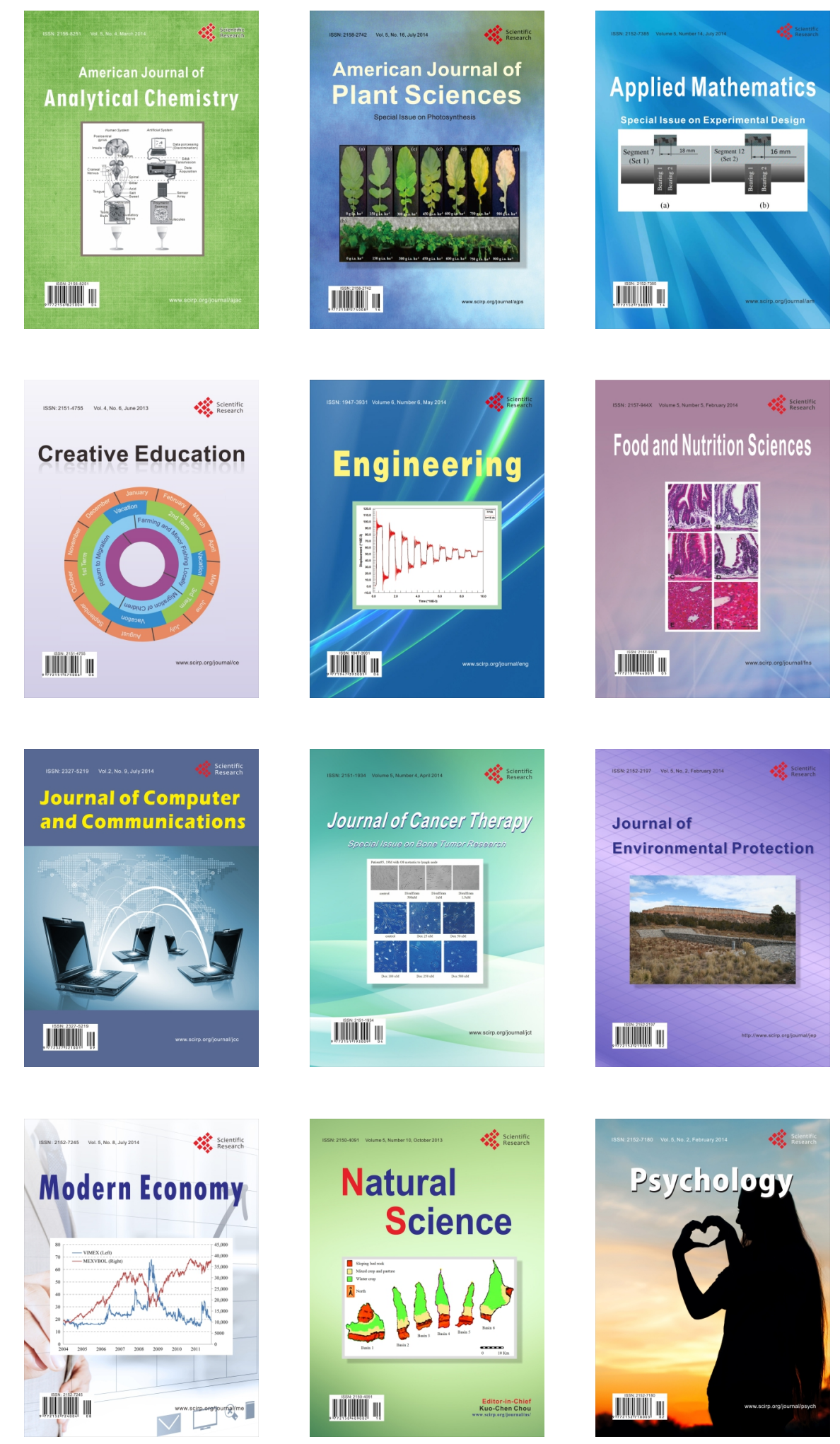